\title{
Association of ventilator type with hospital mortality in critically ill patients with SARS-CoV2 infection: a prospective study
}

\author{
Alexis Ferré ${ }^{*} \mathbb{D}$, Fabien Marquion², Marc Delord ${ }^{3,4}$, Antoine Gros ${ }^{1}$, Guillaume Lacave ${ }^{1}$, Virginie Laurent ${ }^{1}$, \\ Sybille Merceron ${ }^{1}$, Marine Paul ${ }^{1}$, Christelle Simon², Gilles Troché ${ }^{1}$, Clément Charbonnel ${ }^{5}$, \\ Stéphanie Marque-Juillet ${ }^{6}$, Fabrice Bruneel ${ }^{1}$ and Stéphane Legriel ${ }^{1,7}$ on behalf of the RESPI-COVID19 Study \\ Group
}

\begin{abstract}
Background: To evaluate the association between ventilator type and hospital mortality in patients with acute respiratory distress syndrome (ARDS) related to COVID-19 (SARS-CoV2 infection), a single-center prospective observational study in France.

Results: We prospectively included consecutive adults admitted to the intensive care unit (ICU) of a universityaffiliated tertiary hospital for ARDS related to proven COVID-19, between March 2020 and July 2021. All patients were intubated. We compared two patient groups defined by whether an ICU ventilator or a less sophisticated ventilator such as a sophisticated turbine-based transport ventilator was used. Kaplan-Meier survival curves were plotted. Cox multivariate regression was performed to identify associations between patient characteristics and hospital mortality. We included 189 patients (140 [74.1\%] men) with a median age of 65 years [IQR, 55-73], of whom 61 (32.3\%) died before hospital discharge. By multivariate analysis, factors associated with in-hospital mortality were age $\geq 70$ years $(\mathrm{HR}, 2.11 ; 95 \% \mathrm{Cl}, 1.24-3.59 ; P=0.006)$, immunodeficiency $(\mathrm{HR}, 2.43 ; 95 \% \mathrm{Cl}, 1.16-5.09 ; P=0.02)$ and serum creatinine $>100 \mu \mathrm{mol} / \mathrm{L}(\mathrm{HR}, 3.01 ; 95 \% \mathrm{Cl}, 1.77-5.10 ; P<0.001)$ but not ventilator type. As compared to conventional ICU (equipped with ICU and anesthesiology ventilators), management in transient ICU (equipped with non-ICU turbinebased ventilators) was associated neither with a longer duration of invasive mechanical ventilation (18 [IQR, 11-32] vs. 21 [13-37] days, respectively; $P=0.39$ ) nor with a longer ICU stay (24 [IQR, 14-40] vs. 27 [15-44] days, respectively; $P=0.44)$.

Conclusions: In ventilated patients with ARDS due to COVID-19, management in transient ICU equipped with nonICU sophisticated turbine-based ventilators was not associated with worse outcomes compared to standard ICU, equipped with ICU ventilators. Although our study design is not powered to demonstrate any difference in outcome, our results after adjustment do not suggest any signal of harm when using these transport type ventilators as an alternative to ICU ventilators during COVID-19 surge.
\end{abstract}

Keyword: COVID-19, ICU, Ventilator, Mortality, Outcomes

\footnotetext{
*Correspondence: aferre@ch-versailles.fr

${ }^{1}$ Intensive Care Unit, Versailles Hospital, 177 Rue de Versailles, 78150 Le Chesnay, France

Full list of author information is available at the end of the article Members of the RESPI-COVID19 Study Group is listed in Acknowledgements.
}

\section{Take home message}

During COVID-19 pandemics when many healthcare systems were overwhelmed and ICUs saw huge surges in admissions, using sophisticated turbine-based transport ventilators after admission was associated neither 
with higher in-hospital mortality nor with longer invasive mechanical ventilation duration in critically ill patients with SARS-CoV2 infection-related ARDS. Although our study design is underpowered to demonstrate outcome differences, our results do not suggest any signal of harm when using these transport type ventilators as an alternative to ICU ventilators during COVID-19 surge.

\section{Background}

The current COVID-19 pandemic, caused by the SARS$\mathrm{CoV} 2$ virus, is evolving in waves that put healthcare systems under severe strain [1-4]. Nearly $10 \%$ of patients with COVID-19 have severe acute respiratory distress syndrome (ARDS) that requires admission to the intensive care unit (ICU) and, in many cases, invasive mechanical ventilation (MV) [5-9]. As a consequence, waves of COVID-19 often stretch the available ICU resources far beyond their intended limits [10]. Transient ICU beds must then be created in operating rooms, emergency departments, and other parts of the hospital. These beds need to be equipped, most importantly with competent staff and with ventilators.

The management of ARDS relies on lung-protective ventilation according to international recommendations [11]. Not all existing ventilators have the technical capabilities required for optimal lung-protective ARDS ventilation, nor the possibility of close monitoring the plateau and driving pressures and compliance. In many hospitals, surges in ICU admissions during waves of COVID-19 result in a shortage of sophisticated ICU ventilators. To fill this gap, simpler ventilators such as those designed for patient transport are used. These simpler transport ventilators could be less efficient for the treatment of ARDS, because their intrinsic performances and/or lung monitoring may be insufficient. Moreover, physiological studies have demonstrated an influence of ventilator type on patient comfort, work of breathing, and patient-ventilator asynchronies, with considerable variations across ventilator models [12]. An investigation of the potential association between the use of transport ventilators and the survival of patients with COVID-19-related ARDS was, therefore, timely.

The primary objective of this study was to look for an association linking the type of ventilator used (ICU ventilators, including conventional ICU- and anesthesia ventilator vs. sophisticated turbine-based transport ventilators) and hospital mortality in patients requiring MV for COVID-19-related ARDS. The secondary objectives were to look for associations linking ventilator type to invasive MV duration, ventilation outcomes (prone positioning, rescue inhaled nitric oxide and extracorporeal membrane oxygenation [ECMO]), ICU-length of stay and day-90 mortality.

\section{Methods}

This single-centre observational prospective study was approved by the ethics committee of the French Intensive Care Society (\#20-42) and registered at the French National Institute for Health Data (\#MR 4109060520). Informed consent was sought from the next of kin, if available, and from the patients upon recovery of competency, in compliance with French law.

\section{Patients}

Consecutive adults admitted between March 5, 2020 and July 6, 2021, to one of the four Versailles hospital ICUs for severe proven SARS-CoV2 infection were prospectively included in the RESPI-COVID19 registry. For the analysis of this study, only patients with ARDS related to severe SARS-CoV2 infection requiring invasive MV were eligible. Patients who received MV for causes other than respiratory failure (e.g., non-hypoxic cardiac arrest, cardiogenic or septic shock, neurological disorder, or pregnancy-related disease) were not included.

\section{Study setting and COVID-19 surge}

The Versailles Hospital is a university-affiliated tertiary hospital in the Paris area with 800 medical and surgical beds. The 28-bed closed ICU has 20 ICU beds and 8 intermediate-care beds for continuous monitoring. In March 2020, the first wave of COVID-19 produced a sudden and massive increase in the numbers of patients with ARDS requiring critical care. Transient ICU beds for COVID-19 patients were set up in the intermediatebed unit, the post-anesthesia care units, and the cardiology ICU. The total number of ICU beds was then 49 , in four different places in the hospital. ICU ventilators were available for 27 beds. The remaining 22 beds were equipped with non-ICU (transport) ventilators. During the second and the third wave, transient ICU beds for COVID-19 patients were set up once again.

Dedicated ICU teams (paramedics and physicians) operated in usual ICU unit and the transient ICU from the intermediate-bed unit ( 28 beds). Anesthesiologist teams (paramedics and physicians) operated in the transient ICUs from the post-anesthesia care units (15 beds). A written protocol for COVID-19 related ARDS management was disseminated at the start of the epidemic and then regularly updated (according to scientific knowledge and guidelines at this time). The ICU team participated to dedicated staff in the transient ICUs.

The choice of hospitalization ICU area was first made based on bed availability and on individual patient renal support needs as renal replacement therapy was available only in the conventional ICU. 


\section{Definitions}

Proven SARS-CoV2 infection was defined as a positive reverse transcriptas-polymerase chain reaction (RTPCR) result for SARS-CoV2 obtained on a respiratory tract sample (nasal or nasopharyngeal swab, tracheal aspirate, or bronchial aspirate).

We defined two groups of patients based on ventilator type according to published comparative bench test results [13-18]. The ICU group, so called ICU-ventilator, comprised the high-performance devices used in our ICUs (e.g., Evita XL or Evita Infinity C500 ${ }^{\circledR}$, Dräger, Lübeck, Germany; Carescape R860 ${ }^{\circledR}$, General Electrics Healthcare, Boston, MA, USA) or in operating rooms (e.g., Aisys $\mathrm{CS}^{\circledR}{ }^{\circledR}$, Datex Ohmeda, General Electrics Healthcare). The non-ICU group, so-called transportventilator, comprised sophisticated turbine-based ventilators generally designed for mobile interventions but used in transient ICUs set up to handle the surge of patients with severe COVID-19 (e.g., Monnal T60 and T75 ${ }^{\circledR}$, Air Liquide Healthcare, Paris, France; Elisée 350 and $250^{\circledR}$, ResMed, Saint-Priest, France). Because of the surge, bed availability, opening and then closing transient ICUs to face the evolving crisis, some patients were ventilated with both ventilator type during the study period. For these patients, classification group was defined according to composite criteria regarding ventilator type used during the first 10 days of the acute phase of ARDS management, and the ratio period time of the entire invasive MV duration for the eligible ventilator type. Heat and moisture exchanger were used during wave 1 then heated humidifiers during wave 2 and 3.

\section{Standardized ICU management of patients with COVID-19-related ARDS}

The same standardized care management was used at all four ICU sites. At the early phase of the pandemic (first wave), whether virus aerosolization could occur with non-invasive ventilation (NIV) and/or high-flow nasal oxygen (HFNO) was unknown. Consequently, conventional oxygen therapy via a face mask was the preferred, albeit not exclusive, modality of initial oxygen administration [19]. The criteria for invasive $M V$ initiation were persistent severe hypoxemia $\left(\mathrm{SpO}_{2}<90 \%\right.$ despite $12-15 \mathrm{~L} / \mathrm{min}$ face-mask oxygen or $\mathrm{FiO}_{2}=100 \%$ on NIV or HFNO) or persistent clinical signs of acute respiratory distress. Patients with ARDS as defined by the Berlin classification received invasive MV (volume assist controlled ventilation mode, tidal volume of $6 \mathrm{~mL} / \mathrm{kg}$ of predicted body weight, positive end-expiratory pressure regarding $\mathrm{FiO}_{2}$ level with respect to plateau pressure $\leq 28-30 \quad \mathrm{cmH}_{2} \mathrm{O}$ ), sedative drugs, neuromuscular blockade and prone positioning in compliance with international guidelines [11, 20-23]. Inhaled nitric oxide and/or recruitment maneuvers were performed as rescue therapy if deemed necessary by the physician in charge. The appropriateness of using rescue ECMO was discussed collegially with referral center specialists (ICU, Pitié-Salpêtrière Teaching Hospital, Paris, France) in all patients with prespecified criteria [24-26]. Prophylactic anticoagulation was given in a standard dosage based on patient weight until March 25 and in an intermediate dosage thereafter [27-29]. Bacterial co-infection at admission or during the ICU stay was carefully screened for and treated as appropriate.

Since summer 2020 and the positive results of the RECOVERY study on steroids efficacy for hypoxemic SARS-CoV2 patients [30], international guidelines had recommended [31] their use for all critical patients requiring supplemental oxygen. Patients admitted since July 25, 2020 received intravenous dexamethasone $6 \mathrm{mg}$ per day for 10 days. In addition, preliminary data on risk contamination (viral aerosolization) leads to reassurance for non-invasive ventilatory assistance, such as HFNO and face-mask NIV [32-34]. At this time, we used HFNO as first line oxygen therapy for all patients admitted since July 25, 2020 for a de novo acute respiratory failure related to a proven SARS-CoV2 infection.

Rescue intravenous dexamethasone therapy, $20 \mathrm{mg} /$ day for 5 days followed by $10 \mathrm{mg} /$ day for 5 days could be initiated for patients with persistent moderate-to-severe ARDS $\left(\mathrm{PaO}_{2} / \mathrm{FiO}_{2}<150\right)$ and low respiratory static compliance $\left(<30 \mathrm{~mL} / \mathrm{cmH}_{2} \mathrm{O}\right)$ despite ventilator setting optimization, intravenous neuromuscular blocking agent infusion, and prone positioning $[20,35,36]$.

\section{Data collection}

Data for each patient were collected into an electronic file (Excel ${ }^{\circledR}$, Microsoft, Redmond, WA) whose access was restricted by a code known only by the data collector $[\mathrm{AF}]$. The data files were anonymized by assigning a number to each patient. We collected demographic characteristics and comorbidities. Clinical and laboratory findings at ICU admission were recorded. The last $\mathrm{PaO}_{2} /$ $\mathrm{FiO}_{2}$ ratio before intubation was calculated using the following formula for patients without NIV or HFNO: $\mathrm{PaO}_{2} /\left(\mathrm{FiO}_{2}=0.21+0.03 \times \mathrm{O}_{2}\right.$ in $\mathrm{L} /$ min delivered nasally or through a face-mask) [37]. The following data were also collected: severity and description of organ failures according to the Simplified Acute Physiology score II (SAPS-II) [38] and the Sepsis-related Organ Failure Assessment (SOFA) score [39], the use of prone positioning, inhaled nitric oxide, vasoactive drugs, renal replacement therapy, and ECMO.

We recorded the ventilator device used from ICU admission to ICU discharge, total MV duration, and total 


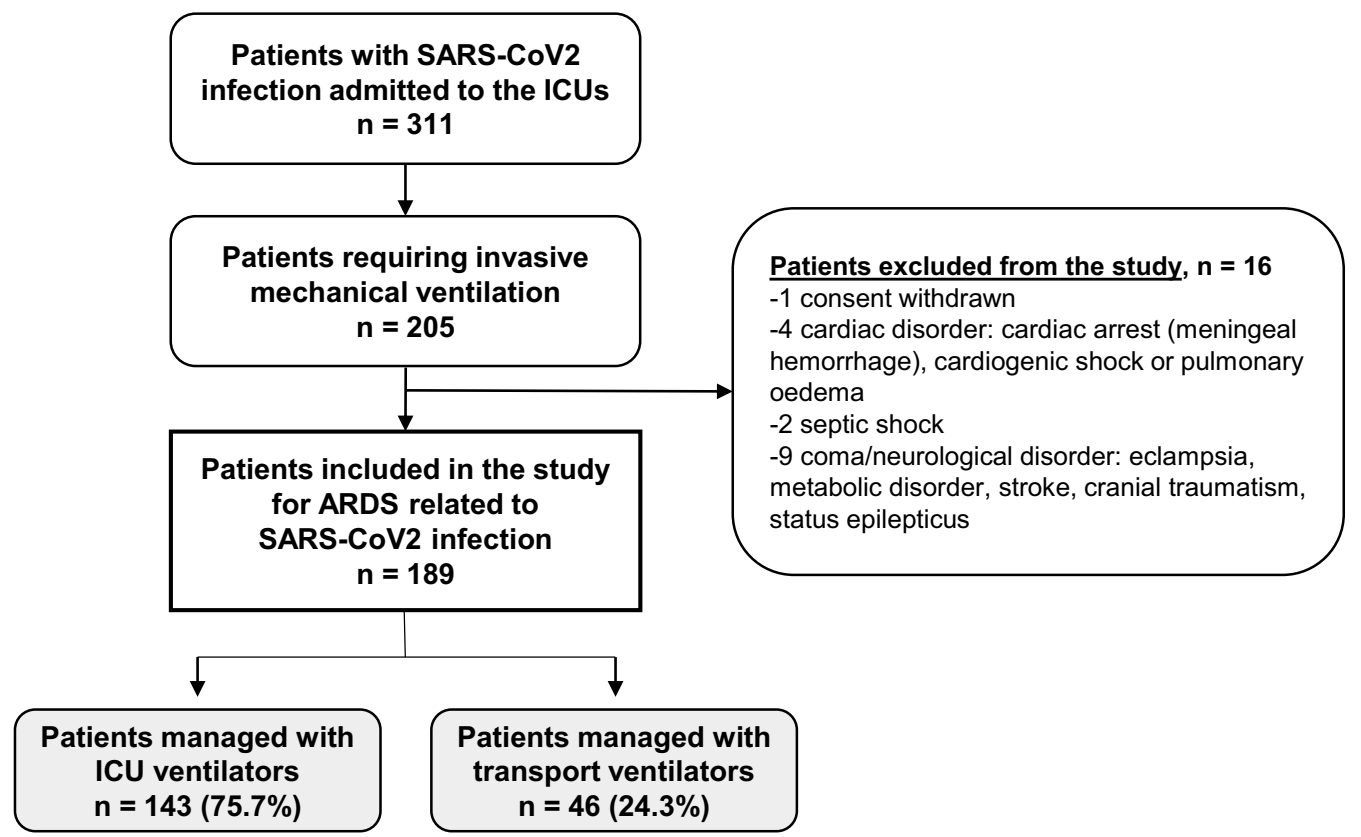

Fig. 1 Patient flowchart. SARS-CoV2 severe acute respiratory syndrome-coronavirus type 2, ARDS acute respiratory distress syndrome, ICU intensive care unit

NIV and/or HFNO duration if relevant. Finally, we collected ICU and hospital lengths of stay, ICU mortality, in-hospital mortality, and day-90 mortality (based on hospital medical records and follow-up, rehabilitationcare unit data, or general practitioner data at day-90).

\section{Statistical analysis}

Quantitative parameters were described as median [interquartile range] and qualitative parameters as number (percentage). We compared categorical variables using Fisher's exact tests and continuous variables using Wilcoxon rank-sum tests.

Survival curves were obtained using the Kaplan-Meier estimator and data were censored at day-90 according to vital status. To identify associations between patient characteristics and hospital mortality, a Cox proportional hazard analysis was performed for each variable. A multivariate model was then built with variables that yielded $P$ values smaller than 0.05 by univariate analysis and/or were clinically relevant according to the present study or previous published data on severe COVID-19 (ventilator type, age, immunodeficiency, last $\mathrm{PaO}_{2} / \mathrm{FiO}_{2}$ ratio before invasive mechanical ventilation, creatininemia at ICU admission, dexamethasone initiated at ICU admission). Missing data were imputed using multivariate imputation by chained equations.

To better evaluate the effect of ventilator exposure on hospital mortality, we conducted an ancillary propensity score matching analysis. Used variables (age, male sex, time from hospitalization to ICU admission, SAPS II, respiratory SOFA score and hepatic SOFA score, creatinine at ICU admission $\geq 100 \mu \mathrm{mol} / \mathrm{L}$ and $\mathrm{LDH}$ value at ICU admission) were associated to both ventilator exposure and outcome [40]. Matching tended to reach 1:2 given a 0.28 caliper on the logit of the propensity score [41].

All tests were two-sided and $P$ values $<0.05$ were considered significant. Analyses were performed using the $\mathrm{R}$ statistical program version 4.0.3 (R Foundation for Statistical Computing, Vienna, Austria). ${ }^{1}$

\section{Results}

\section{Patients}

Figure 1 shows the patient flowchart. Of the 311 critically ill patients with a positive RT-PCR for SARS-CoV2 managed in the four COVID-19 ICUs between March 5, 2020 and July 6, 2021, 189 were included in the study.

Table 1 reports the main patients characteristics. There were $140(74.1 \%)$ men with a median age of 65 [IQR, $57-73]$ years. Obesity $\left(B M I \geq 30 \mathrm{~kg} / \mathrm{m}^{2}\right)$ was present in $70(37.2 \%)$ patients and a history of arterial hypertension and diabetes mellitus in 87 (46\%) and $55(29.1 \%)$ patients, respectively. Median time from symptom onset to ICU admission was 9 [IQR, 6-11] days.

\footnotetext{
${ }^{1}$ http://www.R-project.org. Accessed April 02, 2021.
} 
Table 1 Baseline and ICU admission characteristics according to ventilator type in patients with acute respiratory distress syndrome due to COVID-19

\begin{tabular}{|c|c|c|c|c|c|}
\hline Variables & $\begin{array}{l}\text { All patients } \\
n=189\end{array}$ & $\begin{array}{l}\text { ICU ventilator } \\
n=143(75.7)\end{array}$ & $\begin{array}{l}\text { Transport } \\
\text { ventilator } \\
n=46(24.3)\end{array}$ & $P$ value & $N$ missing ${ }^{a}$ \\
\hline \multicolumn{6}{|l|}{$\begin{array}{l}\text { Demographic char- } \\
\text { acteristics }\end{array}$} \\
\hline Age (years) & 65 [57-73] & 65 [56-74] & 65 [60-73] & 0.90 & \\
\hline Male sex & $140(74.1)$ & $112(78.3)$ & $28(60.9)$ & 0.03 & \\
\hline Active smoking & $11(6.0)$ & $9(6.4)$ & $2(4.4)$ & 1.00 & 4 \\
\hline \multicolumn{6}{|l|}{ Comorbidities } \\
\hline $\begin{array}{l}\text { Coronary artery } \\
\text { disease }\end{array}$ & $18(9.5)$ & $14(9.8)$ & $4(8.7)$ & 1.00 & \\
\hline $\begin{array}{l}\text { Treated arterial } \\
\text { hypertension }\end{array}$ & $87(46.0)$ & $69(48.3)$ & $18(39.1)$ & 0.31 & \\
\hline Diabetes mellitus & $55(29.1)$ & $45(31.5)$ & $10(21.7)$ & 0.26 & \\
\hline $\begin{array}{l}\text { Immunodefi- } \\
\text { ciency }\end{array}$ & $18(9.5)$ & $15(10.5)$ & $3(6.5)$ & 0.57 & \\
\hline $\begin{array}{l}\text { Obesity } \\
\left(\mathrm{BMl} \geq 30 \mathrm{~kg} / \mathrm{m}^{2}\right)\end{array}$ & $70(37.2)$ & $56(39.4)$ & $14(30.4)$ & 0.30 & 1 \\
\hline Asthma & $15(7.9)$ & $10(7.0)$ & $5(10.9)$ & 0.37 & \\
\hline COPD & $10(5.3)$ & $8(5.6)$ & $2(4.4)$ & 1.00 & \\
\hline Bronchectasis & $2(1.1)$ & $2(1.4)$ & $0(0.0)$ & 1.00 & \\
\hline \multicolumn{6}{|l|}{$\begin{array}{l}\text { Characteristics at ICU } \\
\text { admission }\end{array}$} \\
\hline $\begin{array}{l}\text { Epidemic COVID- } \\
19 \text { wave }\end{array}$ & & & & 0.23 & \\
\hline Wave 1 & $82(43.4)$ & $66(46.2)$ & $16(34.8)$ & & \\
\hline Wave 2 & 37 (19.6) & $29(20.3)$ & $8(17.4)$ & & \\
\hline Wave 3 & $70(37.0)$ & 48 (33.6) & $22(47.8)$ & & \\
\hline SAPS II & 40 [34-49] & $41[34-50]$ & 40 [35-45] & 0.45 & \\
\hline $\begin{array}{l}\text { Day } 1 \text {, total SOFA } \\
\text { score }^{b}\end{array}$ & $6[4-7]$ & $6[4-7]$ & $6[4-7]$ & 0.72 & 1 \\
\hline $\begin{array}{l}\text { Respiratory SOFA } \\
\text { score }\end{array}$ & $3[3,4]$ & $3[3,4]$ & $3[-4]$ & 0.18 & \\
\hline $\begin{array}{l}\text { Cardiovascular } \\
\text { SOFA score }\end{array}$ & $3[0-3]$ & $3[0-3]$ & $3[0-3]$ & 0.96 & \\
\hline Renal SOFA score & $0[0-0]$ & $0[0-1]$ & $0[0-0]$ & 0.28 & 1 \\
\hline $\begin{array}{l}\text { Neurological SOFA } \\
\text { score }\end{array}$ & $0[0-0]$ & $0[0-0]$ & $0[0-0]$ & 0.89 & \\
\hline $\begin{array}{l}\text { Hepatic SOFA } \\
\text { score }\end{array}$ & $0[0-0]$ & $0[0-0]$ & $0[0-0]$ & 0.13 & 1 \\
\hline $\begin{array}{l}\text { Coagulation SOFA } \\
\text { score }\end{array}$ & $0[0-0]$ & $0[0-0]$ & $0[0-1]$ & 0.28 & 1 \\
\hline $\begin{array}{l}\text { Time from symp- } \\
\text { tom onset to ICU } \\
\text { admission (days) }\end{array}$ & $9[6-11]$ & $8[6-12]$ & $9[6-11]$ & 0.84 & 1 \\
\hline $\begin{array}{l}\text { Time from hospi- } \\
\text { talization to ICU } \\
\text { admission (days) }\end{array}$ & $1[0-3]$ & $1[0-3]$ & $2[0-4]$ & 0.04 & 1 \\
\hline $\begin{array}{l}\text { Pulmonary co- } \\
\text { infection at ICU } \\
\text { admission }\end{array}$ & $16(8.5)$ & $13(9.1)$ & $3(6.5)$ & 0.70 & \\
\hline $\begin{array}{l}\text { Oxygen require- } \\
\text { ments at ICU } \\
\text { admission }(L / m i n)\end{array}$ & 15 [15-15] & 15 [15-15] & 15 [13-15] & 0.71 & 4 \\
\hline $\begin{array}{l}\text { Laboratory tests at } \\
\text { ICU admission }\end{array}$ & & & & & \\
\hline
\end{tabular}


Table 1 (continued)

\begin{tabular}{|c|c|c|c|c|c|}
\hline Variables & $\begin{array}{l}\text { All patients } \\
n=189\end{array}$ & $\begin{array}{l}\text { ICU ventilator } \\
n=143 \text { (75.7) }\end{array}$ & $\begin{array}{l}\text { Transport } \\
\text { ventilator } \\
n=46(24.3)\end{array}$ & $P$ value & $N$ missing ${ }^{a}$ \\
\hline Lactate (mmol/L) & $1.5[1.2-1.9]$ & $1.6[1.3-2.0]$ & 1.4 [1.2-1.7] & 0.03 & 1 \\
\hline LDH (IU/L) & 724 [532-915] & 759 [609-1002] & 580 [464-763] & $<0.001$ & 3 \\
\hline $\begin{array}{l}\text { Lymphocytes } \\
(\mathrm{G} / \mathrm{L})\end{array}$ & $0.66[0.45-0.95]$ & $0.70[0.45-1.00]$ & $0.62[0.43-0.84]$ & 0.17 & 6 \\
\hline $\begin{array}{l}\text { C-reactive protein } \\
(\mathrm{mg} / \mathrm{L})\end{array}$ & 167 [94-242] & 170 [95-245] & 147 [86-200] & 0.25 & 23 \\
\hline $\begin{array}{l}\text { Procalcitonin (ng/ } \\
\mathrm{mL} \text { ) }\end{array}$ & $0.4[0.2-1.1]$ & $0.4[0.2-1.3]$ & $0.3[0.2-0.7]$ & 0.16 & 26 \\
\hline D-dimers (ng/mL) & 1525 [883-2550] & 1750 [970-2650] & 1090 [770-1730] & 0.02 & 27 \\
\hline $\begin{array}{l}\text { Creatinine } \\
(\mu \mathrm{mol} / \mathrm{L})\end{array}$ & 73 [60-98] & 78 [62-101] & $66[53-88]$ & 0.02 & 1 \\
\hline Troponin (ng/mL) & $0.01[0.01-0.02]$ & $0.01[0.01-0.03]$ & $0.01[0.01-0.02]$ & 0.44 & 25 \\
\hline $\begin{array}{l}\text { NT-proBNP (pg/ } \\
\mathrm{mL} \text { ) }\end{array}$ & 383 [156-973] & 473 [188-1021] & 311 [143-670] & 0.27 & 70 \\
\hline
\end{tabular}

Data are Presented as $N$ (\%) or median [interquartile range]

$B M I$ body mass index, COPD chronic obstructive pulmonary disease, ICU intensive care unit, SAPS I/ Simplified Acute Physiology Score II, SOFA sepsis-related organ failure assessment, $L D H$ lactate dehydrogenase, CRP NT-proBNP: NT-pro B-type natriuretic peptide

${ }^{\text {a }}$ Number of missing observations, unless $\varnothing$

${ }^{b}$ Six organs or systems are assessed, each receiving 0 (no dysfunction) to 4 points (more severe dysfunction). The sum of scores ranges from 0 to 24 ; higher scores indicate more severe disease

\section{ICU management}

At ICU admission, 16 (8.5\%) of the 189 patients received orotracheal intubation and $\mathrm{MV}$ before ICU admission because of on-scene life-threatening respiratory distress. The remaining 173 non- intubated patients before ICU admission received face-mask supplemental oxygen at a median rate of 15 [IQR, 15-15] $\mathrm{L} / \mathrm{min}$; of these, 112 (59.3\%) were switched to HFNO after ICU admission and 48 (25.4\%) to supplemental NIV. All patients received MV with a median time from ICU admission to intubation of 0 [IQR, 0-1] days. The last $\mathrm{PaO}_{2} / \mathrm{FiO}_{2}$ ratio before intubation was 89 [IQR, 71-123], corresponding to a median $\mathrm{FiO}_{2}$ of $80 \%$ [IQR, $66 \%-100 \%]$.

\section{Comparison according to ventilator type}

Of the 189 patients, $143(75.7 \%)$ were managed with ICU ventilators and $46(24.3 \%)$ with transport ventilators (Table 1). The only baseline differences between the two groups were for male sex percentage, time from hospitalization to ICU admission, lactate, LDH, D-dimers and serum creatinine. The two groups were not significantly different in terms of severity scores during the first $24 \mathrm{~h}$ after ICU admission (SAPS II and specific organ SOFA scores) neither for the use of prone positioning, number of prone position sessions per patient, rescue use of inhaled nitric oxide, rescue use of ECMO, or frequency of ventilator-associated pneumonia (Table 2).

\section{Determinants of hospital mortality}

Figure 2 reports the Kaplan-Meier survival curves in the two ventilator-type groups. Overall in-hospital mortality was $32.3 \%(61 / 189)$ with no significant between-group difference $(P=0.44)$. Results of univariate analysis of the variables associated with hospital mortality are shown in Additional file 1: Table S1. Ventilator type was not associated with hospital mortality in univariate analysis. By multivariate analysis (Fig. 3), the variables significantly associated with hospital mortality were age $\geq 70$ years $(\mathrm{HR}, 2.11 ; 95 \% \mathrm{CI}, 1.24-3.59$; $P=0.006$ ), immunodeficiency (HR, 2.43; 95\%CI, 1.165.09; $P=0.02)$ and serum creatinine $\geq 100 \mu \mathrm{mol} / \mathrm{L}(\mathrm{HR}$, 3.01; 95\%CI, 1.77-5.10; $P<0.001)$ but not ventilator type (ICU vs. transport).

The results of hospital mortality comparison between waves according to ventilator type did not show significant difference: $30 \%$ vs. $19 \%$ during wave $1(P=0.5)$, $34 \%$ vs. $38 \%$ during wave $2(P>0.9)$ and $38 \%$ vs. $32 \%$ during wave $3(P=0.6)$, respectively, for ICU-ventilator group and transport-ventilator group.

The results subset of the propensity score matching analysis was composed of 111 patients, whom 70 were exposed to ICU ventilators and 41 to transport ventilators. This sensitivity analysis produced comparable results without significant difference in hospital mortality rate (30\% in the ICU ventilator group vs. $26.8 \%$ in the transport ventilator group, $P=0.83$ ) (Additional file 1: Table S2). 
Table 2 ICU management and outcomes according to ventilator type in patients with COVID-19-related acute respiratory distress syndrome

\begin{tabular}{|c|c|c|c|c|c|}
\hline Variables & $\begin{array}{l}\text { All patients } \\
n=189\end{array}$ & $\begin{array}{l}\text { ICU ventilator } \\
n=143(75.7)\end{array}$ & $\begin{array}{l}\text { Transport ventilator } \\
n=46(24.3)\end{array}$ & $P$ value & $N$ missing ${ }^{a}$ \\
\hline \multicolumn{6}{|l|}{ ICU management } \\
\hline High-flow nasal oxygen & $112(59.3)$ & $80(55.9)$ & $32(69.6)$ & 0.12 & \\
\hline Non-invasive ventilation & $48(25.4)$ & $33(23.1)$ & $15(32.6)$ & 0.24 & \\
\hline Last $\mathrm{PaO}_{2} / \mathrm{FiO}_{2}$ ratio before intubation & 89 [71-123] & 89 [72-123] & $84[69-113]$ & 0.52 & 28 \\
\hline \multicolumn{6}{|l|}{ Ventilatory settings, first day of ARDS } \\
\hline First $\mathrm{PaO}_{2} / \mathrm{FiO}_{2}$ ratio under invasive $\mathrm{MV}$ & 139 [99-178] & 139 [99-178] & $126[98-174]$ & 0.36 & 2 \\
\hline Corresponding first $\mathrm{FiO}_{2}$ under invasive $\mathrm{MV}$ & $1.0[0.8-1.0]$ & $1.0[0.8-1.0]$ & $0.9[0.7-1.0]$ & 0.02 & 2 \\
\hline Tidal volume (mL/kg PBW) & $6.0[5.9-6.2]$ & $6.0[5.9-6.2]$ & $6.0[6.0-6.1]$ & 0.64 & 3 \\
\hline Set PEEP, $\mathrm{cm} \mathrm{H}_{2} \mathrm{O}$ & $12[10-12]$ & $12[10-12]$ & $12[10-12]$ & 0.69 & 2 \\
\hline Plateau pressure $\left(\mathrm{P}_{\text {PLAT }}, \mathrm{Cm} \mathrm{H}_{2} \mathrm{O}\right)$ & $23[21-25]$ & $23[21-25]$ & $22[20-24]$ & 0.23 & 25 \\
\hline Driving pressure, $\mathrm{cm} \mathrm{H}_{2} \mathrm{O}$ & $10[9-12]$ & $11[9-13]$ & $10[9-11]$ & 0.10 & 25 \\
\hline Time from ICU admission to intubation (days) & $0[0-1]$ & $0[0-1]$ & $0[0-1]$ & 0.34 & 1 \\
\hline Prone positioning & $133(70.4)$ & $99(69.2)$ & $34(73.9)$ & 0.58 & \\
\hline Number of prone position sessions & $4[2-7]$ & $4[2-8]$ & $4[2-6]$ & 0.43 & \\
\hline Inhaled nitric oxide & $52(27.5)$ & $42(29.4)$ & $10(21.7)$ & 0.35 & \\
\hline ECMO & $10(5.3)$ & $10(7.0)$ & $0(0.0)$ & 0.12 & \\
\hline Ventilator-associated pneumonia & $110(58.2)$ & $80(55.9)$ & $30(65.2)$ & 0.31 & \\
\hline Weaning failure ( $\geq 2$ orotracheal intubations) & $27(14.3)$ & $17(11.9)$ & $10(21.7)$ & 0.14 & \\
\hline Tracheostomy & $27(14.3)$ & $20(14.0)$ & $7(15.2)$ & 0.81 & \\
\hline Need for vasoactive drugs in the ICU & $176(93.1)$ & $134(93.7)$ & $42(91.3)$ & 0.52 & \\
\hline Need for renal replacement therapy in the ICU & $28(14.8)$ & $25(17.5)$ & $3(6.5)$ & 0.09 & \\
\hline Dexamethasone initiated at ICU admission & $107(56.6)$ & $77(53.9)$ & $30(65.2)$ & 0.23 & \\
\hline Rescue dexamethasone for persistent ARDS & $38(20.1)$ & $30(21.0)$ & $8(17.4)$ & 0.68 & \\
\hline \multicolumn{6}{|l|}{ Outcomes } \\
\hline Duration of invasive MV, days & $19[11-33]$ & $18[11-32]$ & 21 [13-37] & 0.39 & \\
\hline ICU length of stay (days) & $24[15-41]$ & $24[14-40]$ & $27[15-44]$ & 0.44 & \\
\hline ICU mortality & $60(31.8)$ & $47(32.9)$ & $13(28.3)$ & 0.59 & \\
\hline Post-ICU hospital length of stay (days) & $10[7-15]$ & $11[8-16]$ & $9[7-12]$ & 0.10 & \\
\hline Hospital mortality & $61(32.3)$ & $48(33.6)$ & $13(28.3)$ & 0.59 & \\
\hline Rehabilitation-unit length of stay (days) & $27[17-41]$ & $27[17-41]$ & $31[21-42]$ & 0.68 & \\
\hline Day-90 mortality & $63(33.3)$ & $50(35.0)$ & $13(28.3)$ & 0.47 & \\
\hline
\end{tabular}

Data are presented as $N(\%)$ or Median [interquartile range]

ICU intensive care unit, $\mathrm{PaO}_{2} / \mathrm{FiO}_{2}$ partial pressure of oxygen to fraction of inspired oxygen, $A R D S$ acute respiratory distress syndrome, $P B W$ predicted body weight, $M V$ mechanical ventilation, $P E E P$ positive end-expiratory pressure, $E C M O$ extracorporeal membrane oxygenation, $A R D S$ acute respiratory distress syndrome

${ }^{a}$ Number of missing observations, unless $\varnothing$

\section{Other outcomes}

Table 2 reports the patient outcomes in the two ventilator-type groups. MV duration, ICU mortality, hospital mortality, and day-90 mortality showed no significant between-group differences.

All patients were followed up until day- 90 .

\section{Discussion}

To our knowledge, this study is the first to provide detailed information regarding ICU outcomes according to the ventilator type used in patients with
COVID-19-related ARDS managed during epidemic spikes. Using less sophisticated ventilators instead of ICU ventilators in transient ICU was not significantly associated with ICU, in-hospital, or day-90 mortality. Neither was there any between-group difference in MV duration or in-ICU or hospital lengths of stay. However, our study focused only on two turbine-based non-ICU ventilators.

At the time of our study (March 2020 to July 2021), no etiological treatment had demonstrated efficacy against severe COVID-19. Consequently, the treatment relied on ventilatory assistance, other organ-supportive 


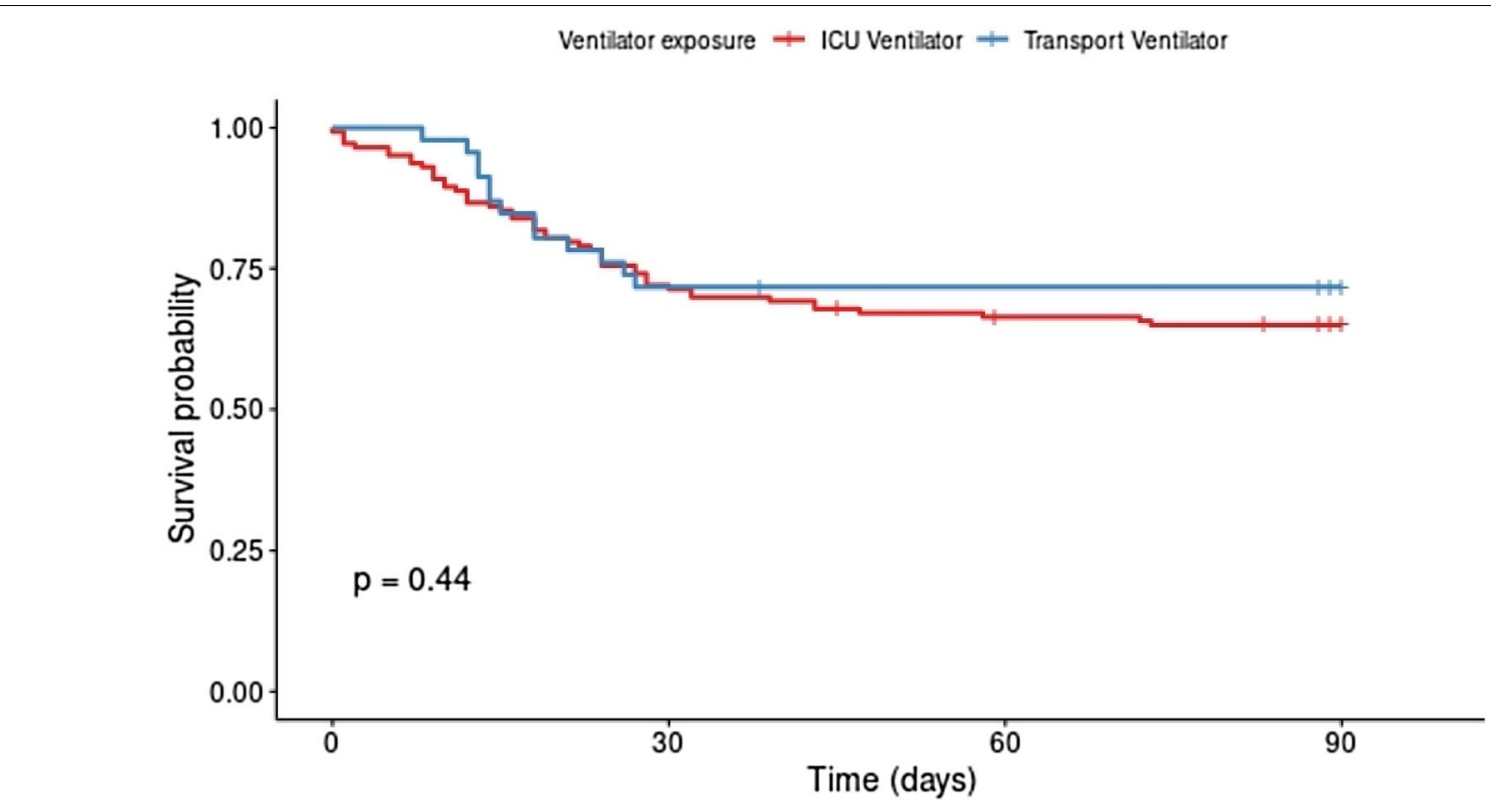

\section{Number at risk}

- 143

$=46$
103

33
93

32
67

27

Fig. 2 Kaplan-Meier survival curves according to ventilator type in 189 patients with COVID-19-related acute respiratory distress syndrome. ICU intensive care unit

\begin{tabular}{|c|c|c|c|c|}
\hline Predictors & $\begin{array}{l}\text { Hazard ratios } \\
(95 \% \mathrm{Cl})\end{array}$ & $P$ value & $\begin{array}{r}\text { Decreased risk of } \\
\text { hospital death }\end{array}$ & $\begin{array}{l}\text { Increased risk of } \\
\text { hospital death }\end{array}$ \\
\hline Transport ventilator & $1.02(0.54-1.92)$ & 0.95 & & \\
\hline Age $\geq 70$ years & $2.11(1.24-3.59)$ & 0.006 & & $\longmapsto$ \\
\hline Immunodeficiency & $2.43(1.16-5.09)$ & 0.02 & & $\square$ \\
\hline Last $\mathrm{PaO}_{2} / \mathrm{FiO}_{2}$ ratio before $\mathrm{MV}$ & $1.00(0.99-1.01)$ & 0.63 & & \\
\hline $\begin{array}{l}\text { Creatinine } \geq 100 \mu \mathrm{mol} / \mathrm{L} \\
\text { at ICU admission }\end{array}$ & $3.01(1.77-5.10)$ & $<0.001$ & & \\
\hline \multirow{3}{*}{$\begin{array}{l}\text { Dexamethasone initiated at ICU } \\
\text { admission }\end{array}$} & $1.35(0.74-2.47)$ & 0.33 & & $\longrightarrow$ \\
\hline & & & & 20 \\
\hline & & & \multicolumn{2}{|c|}{ Adjusted Hazard Ratio $(95 \% \mathrm{Cl})$} \\
\hline
\end{tabular}

Fig. 3 Multivariate analysis and forest plot: association of ventilator type and risk factors with risk of hospital mortality. Data marker sizes reflect the relative size of each covariate. Hazard ratios were computed after adjustment on the SAPS II. Error bars indicate 95\% confidence intervals of hazard ratios. 95\% Cl denotes 95\% confidence interval. ICU intensive care unit 
interventions, and symptomatic anti-inflammatory medications [30]. We focused on patients admitted for COVID-19-related ARDS requiring invasive MV. Of 311 patients admitted to our four ICUs, $66 \%$ were intubated in keeping with previous reports of proportions ranging from 76 to $87 \%$ during the first wave [42-47] and $56 \%$ for patients with high flow nasal oxygen failure [48].

The hospital mortality rate in our study of patients requiring MV was $32.3 \%$, i.e., lower than in previous studies of populations with similar baseline characteristics $[49,50]$. Differences in mortality may be related to differences in selection criteria for ICU admission and/or in bed availability [46]. Median MV duration was 19 days in our study, as compared to 12 days in previous French ICU study [45]. This longer MV duration may have resulted in extubation after the end of virus shedding and/or of clinically significant lung inflammation. Severity scores were generally similar across cohorts, with a median SAPSII of 40 in our study (including only patients requiring invasive $\mathrm{MV}$ ) and 37 in a French nationwide cohort with $38 \%$ hospital mortality [45].

Our study suggests that, when no ICU ventilators are available, the use of sophisticated turbine-based transport ventilators to treat patients with COVID-19-related ARDS may be a valid alternative in transient ICU. Lung protective ventilation with low tidal volume and close lung monitoring is crucial to minimize alveolar damage and mortality in ARDS patients. Artificial ventilators must be able to provide lung protective ventilation during ARDS. Among the ventilators available on the market, especially transport ICU ventilators, not all have the technical performances to achieve such a result. In our study, we classified as ICU-ventilators the anesthesia ventilator Aisys CS2 ${ }^{\circledR}$ (Datex Ohmeda). Even if intrinsic performances are stated as close to standard ICU-ventilators, previous study testing the delivery of tidal volume from anesthesia ventilators during volume-controlled ventilation showed different volume error depending on set tidal volume, compliance, resistance, and delivered fresh gas flow [15]. For the Aisys $\mathrm{CS}^{\circledR}$, results showed a mean of $8-9 \%$ volume error (compliance set to $30 \mathrm{~mL} \mathrm{~cm}{ }^{-1} \mathrm{H}_{2} \mathrm{O}$ ) which could lead to unprotective ventilation. Lyazidi et al. showed a difference between preset and delivered tidal volume $(1-2 \mathrm{~mL} / \mathrm{kg})$ despite intrinsic compensation algorithms in ICU ventilators [16]. The absolute difference was lower but not zero $(<5 \%)$ for Evita XL ${ }^{\circledR}$ (Dräger) used in our study. Regardless of the type of ventilators used, we can observe a difference between performances and delivered ventilation despite optimal settings. However, no test can determine the clinical relevant effect of these error margins. In our study, we evaluated only two sophisticated turbine-based ventilators as transport-ventilators. L'Her et al. classified emergency and transport ventilators according to their performances and technical reliability, even ergonomics: whereas Monnal T75 ${ }^{\circledR}$ (Air Liquide Healthcare) was classified as "ICU-like emergency and transport-ventilators", Monnal T60 ${ }^{\circledR}$ (Air Liquide Healthcare) and Elisée $350^{\circledR}$ (ResMed) were classified as "sophistical emergency and transport ventilators" $[17,18]$. In assist-control mode, three of the four tested transport ventilators both accurately controlled the volume delivered and had acceptable trigger delays in a recent bench study (Michigan test lung); two of the three were the Monnal $\mathrm{T}^{\circ} \mathrm{O}^{\circledR}$ and Elisée $350^{\circledR}$ used in our transient ICUs [51]. Despite these bench tests results, using transport ventilators for ARDS management had never been achieved so far in clinical management for such a large number of patients who required a long invasive MV time. As mechanical models can never mimic all complexities of patient-ventilator interactions, short-time bench tests cannot reflect patient evolving lung ARDS mechanistic across time, and they did not allow making direct conclusion on pulmonary consequences (ventilatory lung injuries). Moreover, one must distinguish between ventilator intrinsic performances and capabilities to lung monitoring to avoid shortcut conclusion. However, our results did not show significant in-between groups differences on MV duration or MV outcomes defined as the need for prone positioning, rescue inhaled NO, ECMO for refractory ARDS nor on ventilatory events (ventilator-associated pneumonia). Our data on MV outcomes/events are consistent with previous publication [45].

We do recognize study limitations. First, patients with the greatest severity of critical illness were given priority for admission to the conventional ICU during the first 3 weeks of the epidemic surge. This might be a high risk of selection bias and could influence our study results. However, since end of March 2020 and because of bed availability, the intermediate-bed unit and the postanesthesia care units operated with direct admissions regardless patients COVID-19 severity, except for those who need renal replacement therapy. Our results did not show significant in-between group difference in terms of ventilator management or severity scores that could have reflect this patient selection bias at ICU admission. The extent to which the more severe critical illness may have cancelled each other out cannot be determined with certainty even if the propensity score matching analysis produced comparable results. Second, the transient ICUs had fewer cubic meters per patient with no wall separations between beds and care was not provided by usual trained ICU teams in the post-anesthesia care units. Thus, being treated with a transport ventilator was associated with many other management differences and it is difficult to conclude that our results are solely a reflection 
of ventilator type, whereas we did not show worse outcomes in transient ICUs. Third, according to international guidelines and as part of quality process, our physicians are sensitised to lung protective ventilation in case of ARDS management. However, we are not able to provide data for the entire MV duration, which could have highlighted differences between groups. Fourth, our results are based on the evaluation of two types of turbine based non-ICU ventilators and they cannot be generalized to all non-ICU transport ventilators. Fifth, the sample size of 189 patients provided limited statistical power to detect significant outcome differences between the two groups (post-hoc power evaluation, Additional file 1). Sixth, our single center study may not reflect all ICUs in countries that have similar health resources. Finally, we did not assess the association of the ICU overload and mortality based on data on ICU bed capacity and transient ICU expansion.

\section{Conclusion}

In our population of critically ill patients with COVID19-related ARDS managed at the beginning of the pandemic, ventilator type as one of several differences in ICU care and so management in transient ICU was not associated with mortality, MV duration, or length of stay. Although our study design is not powered to demonstrate any difference in outcome, our results after adjustment do not suggest any signal of harm when using these transport type ventilators as an alternative to ICU ventilators during the three waves of COVID-19 surge. Multicenter studies of larger populations managed based on the current knowledge of COVID-19-related ARDS are needed to further compare associations between ventilator type and patient outcomes.

\begin{abstract}
Abbreviations
ARDS: Acute respiratory distress syndrome; BMI: Body mass index; COVID-19: Coronavirus disease-2019; CRP: C-reactive protein; ECMO: Extracorporeal membrane oxygenation; ICU: Intensive care unit; IQR: Interquartile range; LDH: Lactate dehydrogenase; MV: Mechanical ventilation; NT-proBNP: NT-pro B-type natriuretic peptide; PCT: Procalcitonin; RT-PCR: Reverse transcriptase-polymerase chain reaction; SAPS II: Simplified Acute Physiology Score II; SARS-CoV2: Severe acute respiratory syndrome-coronavirus 2.
\end{abstract}

\section{Supplementary Information}

The online version contains supplementary material available at https://doi. org/10.1186/s13613-022-00981-2.

Additional file 1: Table S1. Univariate analysis of factors associated with hospital mortality. Table S2. Hospital mortality in ARDS related COVID-19 patients according to ventilator type and matched on a propensity score.

Acknowledgements

We thank the Centre Hospitalier de Versailles for editorial assistance.
Sofia Abbad, Intensive Care Unit, Versailles Hospital, Le Chesnay, France; Georges Abi Abdallah, Intensive Care Unit, Versailles Hospital, Le Chesnay, France; Passem Ahmed, Service de Réanimation-Unité de Soins Continus, Centre hospitalier de Rambouillet, France; Marlène Amara, Department of Microbiology, Versailles Hospital, Le Chesnay, France; Marine Arrayago, Intensive Care Unit, Versailles Hospital, Le Chesnay, France; Alix Aubry, Department of Anesthesiology, Versailles Hospital, Le Chesnay, France; Pauline Bargain, Department of Virology, Versailles Hospital, Le Chesnay, France; Jean-Pierre Bédos, Intensive Care Unit, Versailles Hospital, Le Chesnay, France; Hugo Bellut, Intensive Care Unit, Versailles Hospital, Le Chesnay, France; Michael Benayoun, Intensive Care Unit, Versailles Hospital, Le Chesnay, France; Hotman Benhamida, Intensive Care Unit, Versailles Hospital, Le Chesnay, France; Laura Benchetrit, Intensive Care Unit, Versailles Hospital, Le Chesnay, France; Johan Benhard, Intensive Care Unit, Versailles Hospital, Le Chesnay, France; Emilie Boglietto, Intensive Care Unit, Versailles Hospital, Le Chesnay, France; Raphaelle Bordier, Intensive Care Unit, Versailles Hospital, Le Chesnay, France; Antoine Brizard, Intensive Care Unit, Versailles Hospital, Le Chesnay, France; Amélie Cambriel, Intensive Care Unit, Versailles Hospital, Le Chesnay, France; Steven Causeret, Intensive Care Unit, Versailles Hospital, Le Chesnay, France; Raphaële Convers-Domart, Department of Cardiology, Versailles Hospital, Le Chesnay, France; Paul Chinardet, Intensive Care Unit, Versailles Hospital, Le Chesnay, France; Anaïs Codorniu, Intensive Care Unit, Versailles Hospital, Le Chesnay, France; Adrien Coeffic, Intensive Care Unit, Versailles Hospital, Le Chesnay, France; Wandrille de Carrere, Intensive Care Unit, Versailles Hospital, Le Chesnay, France; Cyril Dekeyser, Intensive Care Unit, Versailles Hospital, Le Chesnay, France; Alix Delaroche, Intensive Care Unit, Versailles Hospital, Le Chesnay, France; Chloé Descamps, Intensive Care Unit, Versailles Hospital, Le Chesnay, France; Juliette Didier, Intensive Care Unit, Versailles Hospital, Le Chesnay, France; Pascaline Dorges, Intensive Care Unit, Versailles Hospital, Le Chesnay, France; Lucie Fanet, Intensive Care Unit, Versailles Hospital, Le Chesnay, France; Camille Fauquenot, Intensive Care Unit, Versailles Hospital, Le Chesnay, France; Claire Flaujac, Department of Haemostasis, Versailles Hospital, Le Chesnay, France; Laura Gouzien, Intensive Care Unit, Versailles Hospital, Le Chesnay, France; Louis Grandière, Intensive Care Unit, Versailles Hospital, Le Chesnay, France; Juliana Henao-Brasseur, Intensive Care Unit, Versailles Hospital, Le Chesnay, France; Jean-Didier Heymann, Service de Réanimation - Unité de Soins Continus, Clinique chirurgicale du Val d'Or, Saint-Cloud, France; Charles Hickel, Intensive Care Unit, Versailles Hospital, Le Chesnay, France; Philippe Jullien, Department of Anesthesiology, Versailles Hospital, Le Chesnay, France; Myriam Lamamri, Intensive Care Unit, Versailles Hospital, Le Chesnay, France; Bénédicte Le Clec'h, Intensive Care Unit, Versailles Hospital, Le Chesnay, France; Marc Lessert, Intensive Care Unit, Versailles Hospital, Le Chesnay, France; Yves Le Tulzo, Infectious Diseases and Medical Intensive Care Unit, Pontchaillou University Hospital, Rennes, France; Bernard Livarek, Department of Cardiology, Versailles Hospital, Le Chesnay, France; Aurélien Maurizot, Department of Cardiology, Versailles Hospital, Le Chesnay, France; Céline Metzger, Department of Anesthesiology, Versailles Hospital, Le Chesnay, France; Hervé Michon, Unité de Réanimation médicale et chirurgicale, Hôpital privé de Parly II, Le Chesnay, France; Marie-Sophie Minin, Intensive Care Unit, Versailles Hospital, Le Chesnay, France; Ghislane Nid-Bella, Department of Anesthesiology, Versailles Hospital, Le Chesnay, France; Marianne Offredo, Intensive Care Unit, Versailles Hospital, Le Chesnay, France; Amael Ouassou, Intensive Care Unit, Versailles Hospital, Le Chesnay, France; Hanna Paktoris, Intensive Care Unit, Versailles Hospital, Le Chesnay, France; François Perier, Intensive Care Unit, Versailles Hospital, Le Chesnay, France; Olivia Picq, Department of Anesthesiology, Versailles Hospital, Le Chesnay, France; Hélène Poirier, Department of Anesthesiology, Versailles Hospital, Le Chesnay, France; JeanHerlé Raphalen, Intensive Care Unit, Versailles Hospital, Le Chesnay, France; Anne Roche, Intensive Care Unit, Versailles Hospital, Le Chesnay, France; Ariane Roujansky, Intensive Care Unit, Versailles Hospital, Le Chesnay, France; Thomas Quenesson, Intensive Care Unit, Versailles Hospital, Le Chesnay, France; Jil Rouaux, Intensive Care Unit, Versailles Hospital, Le Chesnay, France; Lucie Sabau, Department of Anesthesiology, Versailles Hospital, Le Chesnay, France; Marie Saleten, Intensive Care Unit, Versailles Hospital, Le Chesnay, France; Marie Salvetti, Intensive Care Unit, Versailles Hospital, Le Chesnay, France; Florence Sarfati, Department of Anesthesiology, Versailles Hospital, Le Chesnay, France; Pierre Squara, Department of Cardiology and Critical Care, Clinique Ambroise Paré, Neuilly-sur-Seine, France; Celia Teissedre, Intensive Care Unit, Versailles Hospital, Le Chesnay, France; Manon Terris, Intensive Care Unit, Versailles Hospital, Le Chesnay, France; François Stephan, Intensive Care Unit, Marie Lannelongue Hospital (Groupe hospitalier Paris Saint Joseph), Le Plessis-Robinson, 
France; Fabienne Tamion, Centre hospitalier universitaire de Rouen, France; Jean-François Vax, Réanimation polyvalente, Hôpital privé de l'Ouest parisien, Trappes, France; Benoit Veber, Unité d'Anesthésie-Réanimation, Centre hospitalier universitaire de Rouen, France; Cécile Vernet, Department of Anesthesiology, Versailles Hospital, Le Chesnay, France; Alexandre Wormser, Department of Anesthesiology, Versailles Hospital, Le Chesnay, France.

\section{Authors' contributions}

AF contributed to design the study, collected the study data, and contributed to draft the manuscript. SL contributed to design the study and to draft the manuscript. FB contributed to design the study and to draft the manuscript. MD performed the statistical analysis and to draft the manuscript. All authors revised the manuscript for important intellectual content and approved the final version of the manuscript and its submission for publication. All authors read and approved the final manuscript.

\section{Funding}

No funding was received for this study. The study was supported by the French public funding agency Délégation à la Recherche Clinique et à I'Innovation (DRCl), Le Chesnay, France.

\section{Availability of data and materials}

The data sets used and/or analyzed during the current study are available from the corresponding author on reasonable request.

\section{Declarations}

\section{Ethics approval and consent to participate}

This study was approved by the ethics committee of the French Intensive Care Society (\#20-42) and registered at the French National Institute for Health Data (\#MR 4109060520). Informed consent was sought from the next of kin, if available, and from the patients upon recovery of competency, in compliance with French law.

\section{Consent for publication}

Not applicable to this study of anonymized data.

\section{Competing interests}

None of the authors has any competing interest to declare.

\section{Author details}

${ }^{1}$ Intensive Care Unit, Versailles Hospital, 177 Rue de Versailles, 78150 Le Chesnay, France. ${ }^{2}$ Department of Anesthesiology, Versailles Hospital, Le Chesnay, France. ${ }^{3}$ Clinical Research Center, Versailles Hospital, Le Chesnay, France. ${ }^{4}$ Present Address: Department of Population Health Sciences, Faculty of Life Sciences \& Medicine, King's College London, London, UK. ${ }^{5}$ Department of Cardiology, Versailles Hospital, Le Chesnay, France. ${ }^{6}$ Department of Virology, Versailles Hospital, Le Chesnay, France. ${ }^{7}$ University Paris-Saclay, UVSQ, INSERM, CESP, “PsyDev”Team, Villejuif, France.

Received: 1 October 2021 Accepted: 13 January 2022

Published online: 08 February 2022

\section{References}

1. Zhu N, Zhang D, Wang W, Li X, Yang B, Song J, et al. A novel coronavirus from patients with pneumonia in China, 2019. N Engl J Med. 2020;382(8):727-33.

2. Phan LT, Nguyen TV, Luong QC, Nguyen TV, Nguyen HT, Le HQ, et al. Importation and human-to-human transmission of a novel coronavirus in Vietnam. N Engl J Med. 2020;382(9):872-4.

3. Zhou P, Yang X-L, Wang X-G, Hu B, Zhang L, Zhang W, et al. A pneumonia outbreak associated with a new coronavirus of probable bat origin. Nature. 2020;579(7798):270-3

4. Helmy YA, Fawzy M, Elaswad A, Sobieh A, Kenney SP, Shehata AA. The COVID-19 pandemic: a comprehensive review of taxonomy, genetics, epidemiology, diagnosis, treatment, and control. J Clin Med. 2020;9(4):1225.
5. Ruan Q, Yang K, Wang W, Jiang L, Song J. Clinical predictors of mortality due to COVID-19 based on an analysis of data of 150 patients from Wuhan. China Intensive Care Med. 2020;46:846-8.

6. Yang $X, Y u Y, X u$ J, Shu H, Xia J, Liu H, et al. Clinical course and outcomes of critically ill patients with SARS-CoV-2 pneumonia in Wuhan, China: a single-centered, retrospective, observational study. Lancet Respir Med. 2020;8:475-81.

7. Novel Coronavirus Pneumonia Emergency Response Epidemiology Team. The epidemiological characteristics of an outbreak of 2019 novel coronavirus diseases (COVID-19) in China. Zhonghua Liu Xing Bing Xue Za Zhi Zhonghua Liuxingbingxue Zazhi. 2020;41(2):145-51.

8. Grasselli G, Zangrillo A, Zanella A, Antonelli M, Cabrini L, Castelli A, et al. Baseline characteristics and outcomes of 1591 patients infected with SARS-CoV-2 admitted to ICUs of the Lombardy Region, Italy. JAMA. 2020;323:1574.

9. World Health Organization. Clinical management of severe acute respiratory infection (SARI) when COVID-19 is suspected [Internet]. 2020. Disponible sur: https://www.who.int/publications-detail/clinical-manag ement-of-severe-acute-respiratory-infection-when-novel-coronavirus(ncov)-infection-is-suspected.

10. Cowling BJ, Leung GM. Epidemiological research priorities for public health control of the ongoing global novel coronavirus (2019-nCoV) outbreak. Euro Surveill Bull Eur Sur Mal Transm Eur Commun Dis Bull. 2020;25(6).

11. ARDS Definition Task Force, Ranieri VM, Rubenfeld GD, Thompson BT, Ferguson ND, Caldwell $E$, et al. Acute respiratory distress syndrome: the Berlin definition. JAMA. 2012;307(23):2526-33.

12. Thille AW, Lyazidi, Richard J-CM, Brochard L. Evolution des ventilateurs de réanimation [Internet]. Elsevier Msson; 2008. Disponible sur: https:// www.srlf.org/wp-content/uploads/2015/11/0801-Reanimation-Vol17-N1p012_020.pdf.

13. Jaber S, Langlais N, Fumagalli B, Cornec S, Beydon L, Harf A, et al. Performance studies of 6 new anesthesia ventilators: bench tests. Ann Fr Anesth Reanim. 2000;19(1):16-22

14. Garnier M, Quesnel C, Fulgencio J-P, Degrain M, Carteaux G, Bonnet F, et al. Multifaceted bench comparative evaluation of latest intensive care unit ventilators. Br J Anaesth. 2015;115(1):89-98.

15. Wallon G, Bonnet A, Guérin C. Delivery of tidal volume from four anaesthesia ventilators during volume-controlled ventilation: a bench study. $\mathrm{Br}$ J Anaesth. 2013;110(6):1045-51.

16. Lyazidi A, Thille AW, Carteaux G, Galia F, Brochard L, Richard J-CM. Bench test evaluation of volume delivered by modern ICU ventilators during volume-controlled ventilation. Intensive Care Med. 2010;36(12):2074-80.

17. L'Her E, Roy A, Marjanovic N. Bench-test comparison of 26 emergency and transport ventilators. Crit Care Lond Engl. 2014;18(5):506.

18. Marjanovic N, L'Her E. A comprehensive approach for the ergonomic evaluation of 13 emergency and transport ventilators. Respir Care. 2016;61(5):632-9.

19. Bouadma L, Lescure F-X, Lucet J-C, Yazdanpanah Y, Timsit J-F. Severe SARS-CoV-2 infections: practical considerations and management strategy for intensivists. Intensive Care Med. 2020;46(4):579-82.

20. Griffiths MJD, McAuley DF, Perkins GD, Barrett N, Blackwood B, Boyle $A$, et al. Guidelines on the management of acute respiratory distress syndrome. BMJ Open Respir Res. 2019;6(1):e000420.

21. Fan E, Del Sorbo L, Goligher EC, Hodgson CL, Munshi L, Walkey AJ, et al. An Official American Thoracic Society/European Society of Intensive Care Medicine/Society of Critical Care Medicine Clinical Practice Guideline: mechanical ventilation in adult patients with acute respiratory distress syndrome. Am J Respir Crit Care Med. 2017;195(9):1253-63.

22. Fan E, Brodie D, Slutsky AS. Acute respiratory distress syndrome: advances in diagnosis and treatment. JAMA. 2018;319(7):698-710.

23. Guérin C, Reignier J, Richard J-C, Beuret P, Gacouin A, Boulain T, et al. Prone positioning in severe acute respiratory distress syndrome. N Engl J Med. 2013;368(23):2159-68.

24. Combes A, Hajage D, Capellier G, Demoule A, Lavoué S, Guervilly C, et al. Extracorporeal membrane oxygenation for severe acute respiratory distress syndrome. N Engl J Med. 2018;378(21):1965-75.

25. MacLaren G, Fisher D, Brodie D. Preparing for the most critically ill patients with COVID-19: the potential role of extracorporeal membrane oxygenation. JAMA. 2020;323(13):1245-6. 
26. Alhazzani W, Møller MH, Arabi YM, Loeb M, Gong MN, Fan E, et al. Surviving Sepsis Campaign: guidelines on the management of critically ill adults with Coronavirus Disease 2019 (COVID-19). Intensive Care Med. 2020;46(5):854-87.

27. Thachil J, Tang N, Gando S, Falanga A, Cattaneo M, Levi M, et al. ISTH interim guidance on recognition and management of coagulopathy in COVID-19. J Thromb Haemost JTH. 2020;18(5):1023-6.

28. Hunt B, Retter A, McClintock C. Practical guidance for the prevention of thrombosis and management of coagulopathy and disseminated intravascular coagulation of patients infected with COVID-19. Disponible sur: https://b-s-h.org.uk/media/18171/th-and-covid-25-march-2020-final. pdf.

29. Spyropoulos AC, Levy JH, Ageno W, Connors JM, Hunt BJ, Iba T, et al. Scientific and Standardization Committee communication: clinical guidance on the diagnosis, prevention, and treatment of venous thromboem bolism in hospitalized patients with COVID-19. J Thromb Haemost JTH. 2020;18(8):1859-65.

30. RECOVERY Collaborative Group, Horby P, Lim WS, Emberson JR, Mafham $\mathrm{M}$, Bell JL, et al. Dexamethasone in hospitalized patients with Covid-19preliminary report. N Engl J Med. 2020.

31. World Health Organization. Corticosteroids for COVID-19. 2 Sept 2020; Disponible sur: https://www.who.int/publications/i/item/WHO-2019nCoV-Corticosteroids-2020.1.

32. Li J, Fink JB, Ehrmann S. High-flow nasal cannula for COVID-19 patients: low risk of bio-aerosol dispersion. Eur Respir J. 2020;55(5):2000892.

33. Honore PM, Barreto Gutierrez L, Kugener L, Redant S, Attou R, Gallerani A, et al. Compared to NIPPV, HFNC is more dangerous regarding aerosol dispersion and contamination of healthcare personnel: we are not sure. Crit Care Lond Engl. 2020;24(1):482.

34. Li J, Fink JB, Ehrmann S. High-flow nasal cannula for COVID-19 patients: risk of bio-aerosol dispersion. Eur Respir J. 2020:56(4):2003136.

35. Villar J, Ferrando C, Martínez D, Ambrós A, Muñoz T, Soler JA, et al. Dexamethasone treatment for the acute respiratory distress syndrome: a multicentre, randomised controlled trial. Lancet Respir Med. 2020;8(3):267-76.

36. Villar J, Añón JM, Ferrando C, Aguilar G, MuñozT, Ferreres J, et al. Efficacy of dexamethasone treatment for patients with the acute respiratory distress syndrome caused by COVID-19: study protocol for a randomized controlled superiority trial. Trials. 2020;21(1):717.

37. Frat J-P, Thille AW, Mercat A, Girault C, Ragot S, Perbet S, et al. High-flow oxygen through nasal cannula in acute hypoxemic respiratory failure. $\mathrm{N}$ Engl J Med. 2015;372(23):2185-96.

38. Le Gall JR, Lemeshow S, Saulnier F. A new Simplified Acute Physiology Score (SAPS II) based on a European/North American multicenter study. JAMA. 1993;270(24):2957-63.

39. Vincent JL, Moreno R, Takala J, Willatts S, De Mendonça A, Bruining $\mathrm{H}$, et al. The SOFA (Sepsis-related Organ Failure Assessment) score to describe organ dysfunction/failure. On behalf of the Working Group on Sepsis-Related Problems of the European Society of Intensive Care Medicine. Intensive Care Med. 1996;22(7):707-10.

40. Brookhart MA, Schneeweiss S, Rothman KJ, Glynn RJ, Avorn J, Stürmer T. Variable selection for propensity score models. Am J Epidemiol. 2006;163(12):1149-56

41. Austin PC. Optimal caliper widths for propensity-score matching when estimating differences in means and differences in proportions in observational studies. Pharm Stat. 2011;10(2):150-61.

42. Auld SC, Caridi-Scheible M, Blum JM, Robichaux C, Kraft C, Jacob JT, et al. ICU and ventilator mortality among critically ill adults with coronavirus disease 2019. Crit Care Med. 2020;48(9):e799-804.

43. Cummings MJ, Baldwin MR, Abrams D, Jacobson SD, Meyer BJ, Balough EM, et al. Epidemiology, clinical course, and outcomes of critically ill adults with COVID-19 in New York City: a prospective cohort study. Lancet Lond Engl. 2020;395(10239):1763-70.

44. Grasselli G, Greco M, Zanella A, Albano G, Antonelli M, Bellani G, et al. Risk factors associated with mortality among patients with COVID-19 in intensive care units in Lombardy, Italy. JAMA Intern Med. 2020.

45. COVID-ICU Group on behalf of the REVA Network and the COVID-ICU Investigators. Clinical characteristics and day-90 outcomes of 4244 critically ill adults with COVID-19: a prospective cohort study. Intensive Care Med. 2021;47(1):60-73.
46. Karagiannidis C, Mostert C, Hentschker C, Voshaar T, Malzahn J, Schillinger $\mathrm{G}$, et al. Case characteristics, resource use, and outcomes of 10021 patients with COVID-19 admitted to 920 German hospitals: an observational study. Lancet Respir Med. 2020;8(9):853-62.

47. Chang R, Elhusseiny KM, Yeh Y-C, Sun W-Z. COVID-19 ICU and mechanical ventilation patient characteristics and outcomes-a systematic review and meta-analysis. PLoS ONE. 2021;16(2):e0246318.

48. Demoule A, Vieillard Baron A, Darmon M, Beurton A, Géri G, Voiriot G, et al. High-flow nasal cannula in critically III patients with severe COVID19. Am J Respir Crit Care Med. 2020;202(7):1039-42.

49. Botta M, Tsonas AM, Pillay J, Boers LS, Algera AG, Bos LDJ, et al. Ventilation management and clinical outcomes in invasively ventilated patients with COVID-19 (PRoVENT-COVID): a national, multicentre, observational cohort study. Lancet Respir Med févr. 2021;9(2):139-48.

50. Serafim RB, Póvoa P, Souza-Dantas V, Kalil AC, Salluh JIF. Clinical course and outcomes of critically ill patients with COVID-19 infection: a systematic review. Clin Microbiol Infect Off Publ Eur Soc Clin Microbiol Infect Dis. 2021;27(1):47-54

51. Savary D, Lesimple A, Beloncle F, Morin F, Templier F, Broc A, et al. Reliability and limits of transport-ventilators to safely ventilate severe patients in special surge situations. Ann Intensive Care. 2020;10(1):166.

\section{Publisher's Note}

Springer Nature remains neutral with regard to jurisdictional claims in published maps and institutional affiliations.

\section{Submit your manuscript to a SpringerOpen ${ }^{\circ}$ journal and benefit from:}

- Convenient online submission

- Rigorous peer review

- Open access: articles freely available online

- High visibility within the field

Retaining the copyright to your article

Submit your next manuscript at springeropen.com 